\title{
ОБ ЭФФЕКТИВНОСТИ ИСПОЛЬЗОВАНИЯ МЕТОДА ПРОЕКТОВ ДЛЯ ФОРМИРОВАНИЯ ИНОЯЗЫЧНОЙ КОММУНИКАТИВНОЙ КОМПЕТЕНЦИИ У СТУДЕНТОВ ТЕХНИЧЕСКОГО ВУЗА
}

\author{
Черная Ирина Владимировна \\ Научный руководитель: Володарская Елена Борисовна \\ к.П.н., доцент
}

Санкт-Петербургский политехнический университет Петра Великого

Аннотация: В статье показана эффективность применения метода проектов в обучении английскому языку студентов первого курса СанктПетербургского государственного политехнического университета Петра Великого. Приведены результаты формирующего эксперимента с контрольной и экспериментальной группами, в ходе которого проводилось сравнение метода проектов с традиционным способом обучения.

Ключевые слова: метод проектов, проектная технология, иностранный язык, коммуникативный подход.

\section{THE EFFICIENCY OF USING THE PROJECT METHOD FOR THE FOREIGN LANGUAGE COMMUNICATIVE COMPETENCE FORMATION OF TECHNICAL UNIVERSITIES STUDENTS}

Chernaia Irina

Scientific adviser: Volodarskaya Elena Borisovna

\begin{abstract}
The article shows the effectiveness of the project method in teaching English to the first-year students of Peter the Great St. Petersburg Polytechnic University. The results of an educational experiment with the control and experimental groups are presented; during the experiment, the project method was compared with the traditional teaching method.

Key words: project method, project technology, foreign language teaching, communicative approach.

Переход современной России к рыночным условиям, постоянно возрастающий уровень экономического взаимодействия с другими странами и высокая степень конкуренции на рынке труда значительно актуализировали
\end{abstract}


проблему готовности выпускников к будущей профессиональной деятельности. Владение иностранным языком становится одним из важнейших показателей конкурентоспособности современного специалиста и является условием успешной карьеры практически в любой сфере деятельности [1].

В техническом вузе конечной целью обучения иностранному языку является практическое владение разговорно-бытовой речью и языком специальности для активного применения как в повседневном, так и в профессиональном общении. Однако практика преподавания иностранного языка студентам неязыковых специальностей свидетельствует о том, что фактический уровень владения иностранным языком у выпускников не соответствует выдвигаемым требованиям программы. Зачастую обучение иностранному языку студентов технических вузов реализуется стихийно, т.е. сводится к формальному, механическому освоению материала, что приводит к пассивности студентов на занятиях, их незаинтересованности в конечной цели учебного процесса в вузе в целом.

Развитие коммуникативной компетенции является основной целью обучения иностранным языкам и отвечает требованиям концепции модернизации российского образования. А.А. Леонтьев определяет иноязычную коммуникативную компетенцию как «способность средствами изучаемого языка осуществлять речевую деятельность в соответствии с целями и ситуацией общения в рамках той или иной сферы деятельности» [2, с. 24]. Это не просто сумма знаний, умений и навыков, а способность личности к реализации приобретенного в процессе обучения потенциала. Таким образом, преподаватель должен создать условия для формирования коммуникативной компетенции у студентов. В данном случае метод проектов является наименее ресурсозатратным способом для достижения этой цели, поскольку максимально приближен к реальности. В основе метода проектов лежит развитие познавательных навыков учащихся, умений самостоятельно конструировать свои знания, умений ориентироваться в информационном пространстве, развитие критического мышления [3]. Н.И. Запрудский определяет метод проектов как «систему учебно-познавательных приемов, которые позволяют решить ту или иную проблему в результате самостоятельных и коллективных действий учащихся и обязательной презентации результатов их работы» $[4$, c. 14].

Такие ученые как 3.С. Сазонова, И.В. Арифуллин, Л.С. Феофанова, В.Л. Щербакова считают, что «проектно-ориентированное образование решает 
значительное число разных педагогических задач: обеспечивает формирование целого ряда универсальных и профессиональных компетенций, воспитывает у студентов целеустремленность и ответственность, способствует развитию их способностей к рефлексии. Главное достоинство состоит в том, что оно позволяет каждому участнику совместной работы самостоятельно найти “свою позицию" в проекте, выполнить ту задачу, которая ему по настоящему интересна, тем самым выявляет и раскрывает ранее находившееся в латентном состоянии творческие способности личности» [5, с. 114].

В качестве метода исследования эффективности применения метода проектов в формировании коммуникативной компетенции при обучении студентов первого курса неязыковых специальностей был выбран формирующий эксперимент. В нем принимали участие в качестве экспериментальной и контрольной групп студенты 1 курса СанктПетербургского политехнического университета Петра Великого.

\section{Описание эксперимента}

У студентов-участников эксперимента занятия по иностранному языку проходят один раз в неделю продолжительностью 2 академ. часа. На изучение одного раздела (юнита) учебника выделяется 4 занятия (8 академ. часов). Каждый юнит состоит из 4 подтем, дополняющих друг друга, но не повторяющих лексико-грамматический материал, что и позволяет проверить эффективность использования метода проектов. Эксперимент включает в себя проведение двух занятий продолжительностью по 2 академ. часа в каждой группе - контрольной и экспериментальной. Роль экспериментатора заключается в консультировании и психолого-педагогическом сопровождении студентов.

В контрольной группе занятие проводится строго в соответствии с предложенным планом учебно-методического комплекса (УМК) 'Language Leader Intermediate" и включает в себя упражнения на грамматику, лексику, аудирование, чтение и говорение.

В экспериментальной группе занятие проводится с использованием метода проектов и строится по типу ролевой игры. Проектное занятие “Јob Interview" основано на материале УМК “Language Leader Intermediate". В соответствии с классификацией Е.С. Полат [6], данный проект относится к ролево-игровому, практико-ориентированному, внутреннему, групповому, краткосрочному со скрытой координацией. 


\section{Выполнение проекта}

Студенты делятся на 5 подгрупп по 4 человека. В каждой группе студенты должны выбрать одного “hr-менеджера", остальные члены подгруппы являются “соискателями”. Все студенты получают бланк вакансии, на котором указана должность (релевантная направлению подготовки студентов), обязанности и требования к кандидату. Студенты “соискатели” должны оформить личные, настоящие резюме в соответствии с требованиями к кандидату, указанными в вакансии, реальным опытом работы (в случае его отсутствия указывается опыт стажировки, волонтерской деятельности, пройденные курсы и др.), а также подготовиться к устному интервью со студентом "hr-менеджером". Тем временем, студент "hr-менеджер" изучает рекомендации по проведению собеседования, вопросы, которые необходимо задать каждому кандидату и методы оценки квалификации и личных качеств каждого студента “соискателя" для того, чтобы выбрать одного подходящего на должность. Затем в каждой подгруппе студенты проводят “собеседования", ожидающие студенты наблюдают и делают выводы. После проведения всех интервью, студенты "hr-менеджеры" от каждой группы выступают с презентацией результатов - они дают оценку каждому “соискателю”, свои личные рекомендации, объявляют "победителей" - тех, кто, по их мнению, достоин получить работу в компании. Каждой подгруппе на презентацию полученных результатов представляется до 4 минут. Далее - ответы на вопросы присутствующих. Затем следует оценивание результатов проекта студентами и экспериментатором. Группы оценивают работу каждого участника, экспериментатор оценивает работу групп в целом. Результатами проектной деятельности студентов являются резюме, которые можно использовать в будущем для поиска работы, соответствующей направлению подготовки.

\section{Результаты исследования}

По окончанию эксперимента студенты каждой группы выполнили тест по теме "Job Interview", включающий в себя как перевод слов (Задание №1), так и подстановочные задания с предложениями, включающими в себя фразовые глаголы (Задание №2). Общие результаты теста представлены ниже (табл. 1). 
Таблица 1

Результаты тестирования

\begin{tabular}{|c|c|c|}
\hline Параметр сравнения & $\begin{array}{c}\text { Экспериментальная } \\
\text { группа (20 чел.) }\end{array}$ & $\begin{array}{c}\text { Контрольная } \\
\text { группа (17 чел.) }\end{array}$ \\
\hline \% выполнения теста (средний) & 95,86 & 86 \\
\hline Общее кол-во ошибок & 58 & 168 \\
\hline Среднее кол-во ошибок & 2,9 & 9,9 \\
\hline $\begin{array}{c}\text { Среднее кол-во ошибок в } \\
\text { Задании №1 }\end{array}$ & 2,2 & 6 \\
\hline $\begin{array}{c}\text { Среднее кол-во ошибок в } \\
\text { Задании №2 }\end{array}$ & 0,7 & 3,8 \\
\hline
\end{tabular}

На основании представленных данных можно сделать следующий вывод: студенты экспериментальной группы справились с тестом лучше на 9,86\% чем студенты контрольной группы. Среднее количество ошибок с применением метода проектов меньше в 3,4 раза. Особый интерес представляет разница в запоминании отдельных слов и фразовых глаголов. Ниже на рис. 1 и рис. 2 представлена разница в выполнении первого и второго заданий:

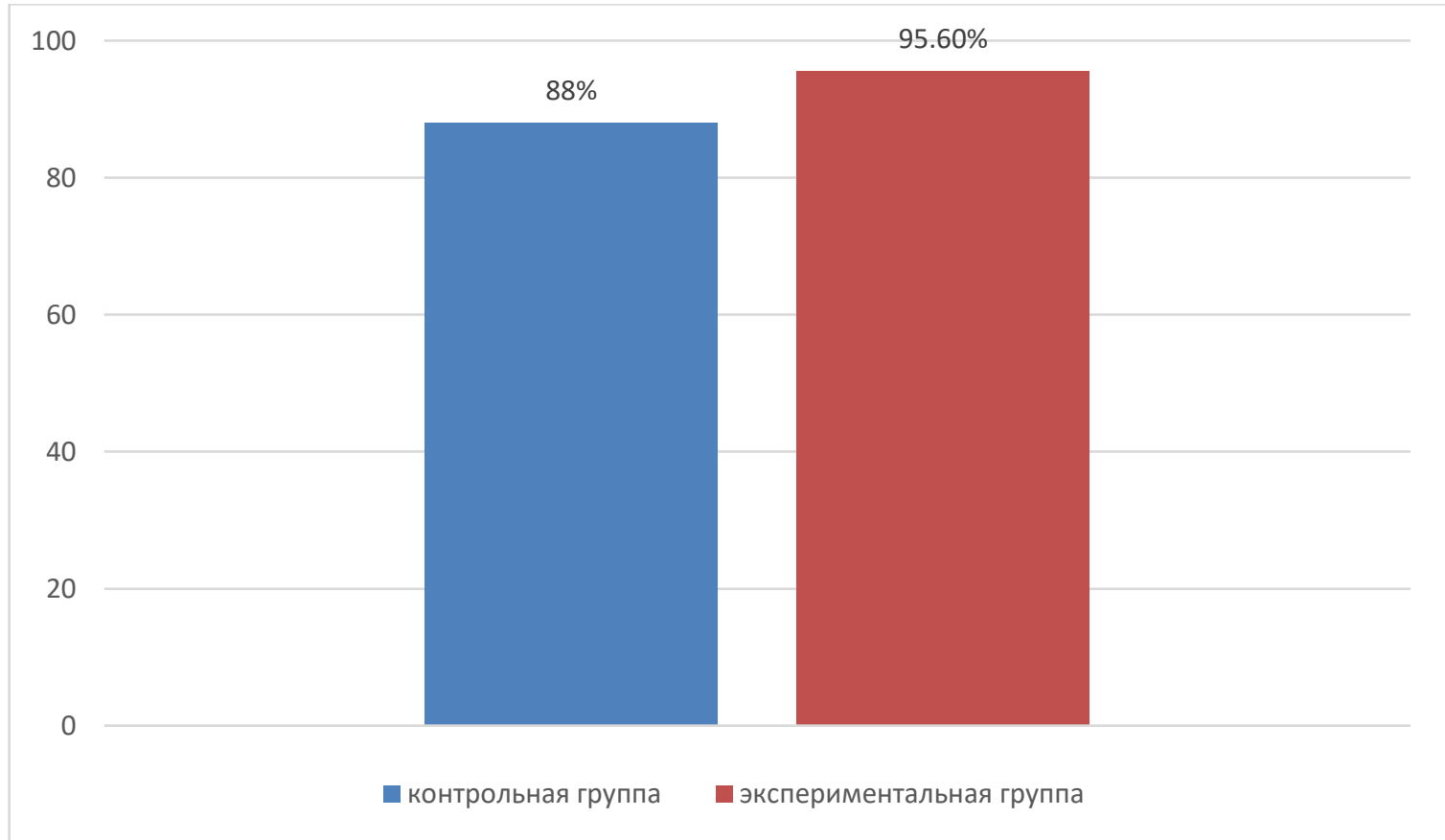

Рис. 1. Результаты выполнения Задания №1 


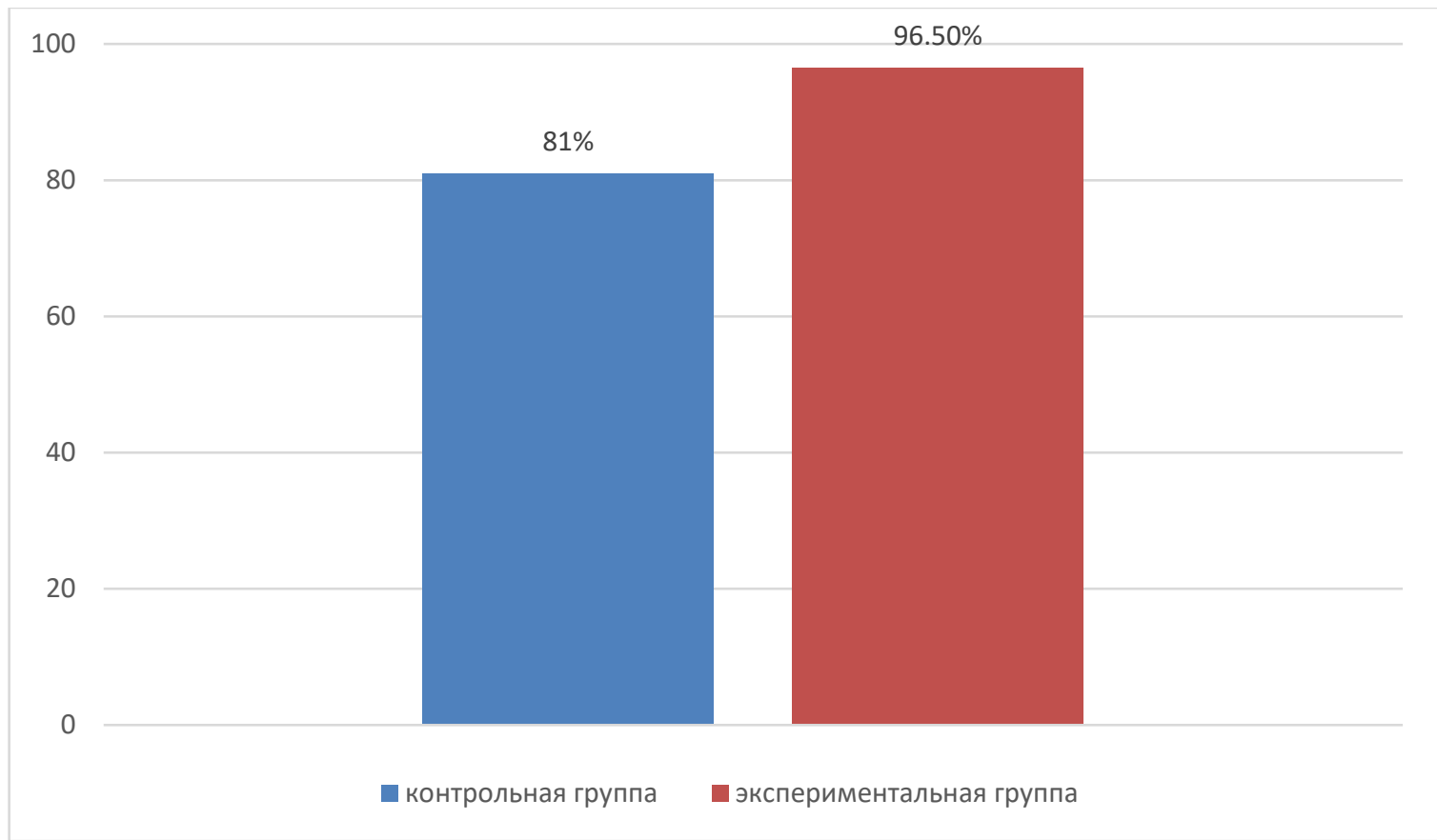

Рис. 2. Результаты выполнения Задания №2

Таким образом, можно сделать вывод, что студенты экспериментальной группы запомнили отдельные слова в 2,7 раз лучше, чем студенты контрольной группы, а фразовые глаголы - в 5,4 раз. Последняя цифра представляет особый интерес для данного исследования, поскольку она является ключевым показателем того, что метод проектов позволяет лучше запомнить фразовые глаголы и выражения, которые являются основой коммуникативной компетенции. Это означает, что даже одно занятие с использованием проектной методики в цикле занятий по одной теме может существенно повлиять на уровень иноязычной подготовки студентов. Также студентам было предложено рассказать, чем было полезно для них данное занятие по проектной методике. Исходя из ответов, многие считают, что навыки составления резюме пригодятся им в будущем в поиске работы, также большинству студентов понравился групповой формат выполнения заданий и наличие разговорной практики.

\section{Заключение}

Эффективность использования метода проектов зависит от качества подготовки педагога к организации учебного проектирования. При планировании проектов необходимо учитывать дидактические принципы последовательности и системности, наглядности, постепенного усложнения материала, чтобы достичь максимальной эффективности проектной работы необходимо четко спланировать все этапы выполнения проекта. Это 
обусловлено в первую очередь тем, что усвоение студентами новой информации в процессе проектной деятельности происходит в сфере неопределенности. Поэтому возникает необходимость проектирования, организации и координации проектной деятельности студентов первого курса, еще не имеющих большого опыта самостоятельного выполнения проектов.

Огромным преимуществом для педагогов является то, что в обучении иностранному языку метод проектов можно использовать в тесном контакте с учебной программой практически по любой теме. Проектная технология может сочетаться с любым УМК или любыми другими учебными средствами и может быть включена в различные формы общей системы работы над изучаемым языком. При этом проектное задание может рассматриваться как определенная форма адаптации материалов учебника к особенностям образовательной ситуации или индивидуальным особенностям учащихся.

Таким образом, результаты проведенного эксперимента могут рассматриваться как подтверждение эффективности применения проектного метода при обучении иностранному языку студентов первого курса технического вуза. Данная модель проекта удовлетворяет запросу современного уровня вузовского образования и способна удовлетворить задачи подготовки и воспитания конкурентоспособного специалиста. Опыт проектной деятельности показал высокие результаты поскольку пассивное усвоение готовых знаний, получаемых от педагога, не может сравниться с активным и творческим подходом.

\section{Список литературы}

1. Гришина А.С. Формирование иноязычной коммуникативнокогнитивной компетенции студентов технического вуза в условиях цифровизации // Современные наукоемкие технологии. - 2020. - № 12 (часть 1) - C. 150-154; URL: http://www.top-technologies.ru/ru/article/view?id=38425 (дата обращения: 13.01.2021).

2. Леонтьев, А.А. Психолого-педагогические основы обновления методики преподавания иностранных языков: Лекция-доклад. / А.А.Леонтьев. М.: Исследовательский центр проблем качества подготовки специалистов, 1998. - 91 c.

3. Полат Е.С. Новые педагогические и информационные технологии в системе образования: учеб. пособие для студ. высш. учеб. заведений / Е.С. Полат, М.Ю. Бухаркина, М.В. Моисеева, А. Е. Петров; под ред. Е. С. Полат. 3-е изд., испр. и доп. - М.: Издательский центр «Академия», 2008. - 272 с. 
4. Запрудский Н.И. Современные школьные технологии: Пособие для учителей. — 2-е изд. / Н.И. Запрудский. — Мн., 2004.—288 с.

5. Сазонова 3.С. Проектно-ориентированное обучение в контексте студенческой жизни / З.С. Сазонова, И.В. Арифуллин, Л.С. Феофанова, В.Л. Щербакова // Высшее образование в России. - Москва, 2015 - № 11 - С. 114 118.

6. Полат Е.С. Метод проектов на уроках иностранного языка // Иностранные языки в школе - 2000. - № 2, 3. - 134 с. 